\title{
Performance of Variables in Screening for Gestational Diabetes
}

\author{
Laura Hautala, ${ }^{1}$ Erling Englund, ${ }^{2}$ Sahruh Turkmen ${ }^{1}$ \\ 1. Department of Clinical Sciences, Obstetrics and Gynaecology, Sundsvalls Research Unit, Umeå University, Umeå, Sweden; 2. Department \\ of Research and Development, Statistic Section, Sundsvall County Hospital, Sundsvall, Sweden
}

ntroduction: Gestational diabetes mellitus (GDM) is associated with adverse pregnancy outcomes. The strategies used to screen for GDM vary both internationally and nationally. Therefore, we investigated the performance of the capillary random plasma glucose (RPG) test, maternal body mass index (BMI) and maternal age in predicting GDM. Methods: In a retrospective cohort study, we included pregnant women without pre-existing diabetes or metabolic disease who gave birth in Västernorrland County, Sweden, in 2015-2016. Values for RPG in gestational weeks 23-28 were obtained from obstetric medical records for each pregnancy. The development of GDM was confirmed by evaluating data in the obstetric records. The ability of RPG, maternal BMI, and age to predict GDM was assessed with receiver-operating characteristic curves. Results: In total, 4,698 pregnancies were included in the final statistical analysis. RPG was fairly effective in screening (area under the curve [AUC] 0.73; 95\% confidence interval [CI] 0.66-0.80), and BMI performed slightly better (AUC 0.75; 95\% CI 0.68-0.82), whereas maternal age performed poorly (AUC $0.61 ; 95 \% \mathrm{Cl} 0.53-0.68$ ). Combining RPG $\geq 7$ and $\mathrm{BMI} \geq 27.9$ yielded the best overall sensitivity (75.4\%), specificity (70.1\%), and AUC $(0.75 ; 95 \% \mathrm{Cl} 0.68-0.82)$. Conclusions: Our results show that the sensitivity of capillary RPG alone in predicting GDM is fair. The combination of RPG with maternal BMI or age showed greater sensitivity. However, none of the screening factors (RPG, BMI, and maternal age), alone or combined, showed sufficiently good performance in predicting GDM.

\section{Keywords}

Random plasma glucose, pregnancy, oral glucose tolerance test (OGTT), body mass index (BMI)

Disclosures: Laura Hautala, Erling Englund and Sahruh Turkmen have no relevant conflicts of interest to declare.

Acknowledgements: This work was supported by a 'SKL-medel' grant from Swedish municipalities and county councils (Sveriges Kommuner och Landsting) in Västernorrland county, Sweden. Review Process: Double-blind peer review. Compliance with Ethics: This study involves a retrospective analysis of data and did not involve any studies with human or animal subjects performed by any of the authors.

Authorship: All named authors meet the International Committee of Medical Journal Editors (ICMJE) criteria for authorship of this manuscript, take responsibility for the integrity of the work as a whole, and have given final approval to the version to be published.

Received: 25 March 2019

Accepted: 5 May 2019

Citation: European Endocrinology. 2019;15(2):101-5

Corresponding Author: Sahruh Turkmen, Clinical Science, Department of Obstetrics and Gynecology, Sundsvall research unit, Umea University, Umeå, Sweden SE 90185. E: sahruh.turkmen@umu.se. www.facebook.com/SahruhTurkmen

Support: No funding was received in the publication of this artice.
Gestational diabetes mellitus (GDM) has traditionally been defined as carbohydrate intolerance, with its onset or first recognition in pregnancy.1.2 The definition, screening and diagnosis of GDM continue to be subjects of controversy. ${ }^{3}$ Recent guidelines have emphasised the importance of the definition of GDM and its distinction from overt diabetes mellitus in pregnancy, because this definition affects the management of the condition during and after pregnancy. ${ }^{4}$ Even a mild degree of hyperglycaemia is associated with a linearly increasing rate of adverse pregnancy outcomes, with no inflection point for risk. ${ }^{5,6}$ Therefore, a diagnostic cut-off value can be considered arbitrary, and this has created confusion about how best to screen for and diagnose GDM.,7

Based on the Hyperglycemia and Adverse Pregnancy Outcomes study, the International Association of Diabetes and Pregnancy Study Group has suggested screening all pregnant women without known pre-existing diabetes or GDM at 24-28 weeks of gestation. The recommended test for screening and diagnosis is the 2-hour $75 \mathrm{~g}$ oral glucose tolerance test (OGTT). ${ }^{8}$ These recommendations have also been adopted by the World Health Organization (WHO). ${ }^{4}$ In contrast, the American College of Obstetricians and Gynecologists (ACOG) suggests that screening should be based on a $50 \mathrm{~g}$ OGTT, followed by a 3-hour $100 \mathrm{~g}$ OGTT, for the diagnosis. ${ }^{9}$ According to the European Association for the Study of Diabetes, the diagnosis of GDM should be based on a $75 \mathrm{~g}$ OGTT. ${ }^{10,11}$ In the UK, the National Institute for Health and Care Excellence (NICE) guideline suggests that previously healthy pregnant women should be screened only if certain risk factors are present. ${ }^{12}$ This approach differs critically from the other well-established guidelines discussed above.

In Sweden, the National Board of Health (Socialstyrelsen) adopted the new WHO and International Association of Diabetes and Pregnancy Study Groups thresholds for the diagnosis of GDM in 2015, but leaves it up to local health authorities to specify the strategy for screening. ${ }^{8,11}$ However, these guidelines do not provide a national recommendation for screening for GDM because the evidence for different screening strategies was found to be inadequate. ${ }^{11}$ The main screening strategy used in sweden is based on repeated measurements of capillary random plasma glucose (RPG) and the assessment of risk factors for the development of GDM. ${ }^{13,14}$ When RPG $\geq 9.0 \mathrm{mmol} / \mathrm{l}$ and/or risk factors for GDM are present, the one-step, 2-hour $75 \mathrm{~g}$ OGTT is recommended in gestational weeks 28-32.15,16

There are several predisposing factors for GDM, including maternal body mass index (BMI) and maternal age. ${ }^{17,18}$ Selective screening may be cost-effective, but risk-factor-based screening has been shown to miss a substantial number of women with GDM..$^{19,20}$ The use of other strategies, 
Table 1: Indications for a 2-hour $75 \mathrm{~g}$ oral glucose tolerance test

\begin{tabular}{|c|}
\hline $\mathrm{RPG} \geq 9.0 \mathrm{mmol} / \mathrm{l}$ \\
\hline GDM in a previous pregnancy \\
\hline Family history of type 2 diabetes mellitus in a first-degree relative \\
\hline $\begin{array}{l}\text { History of LGA (defined as birth weight }>2 \text { SD of the expected birth weight for } \\
\text { gestational age according to the Swedish standard for intrauterine growth) }{ }^{34}\end{array}$ \\
\hline $\begin{array}{l}\text { Previous abortion due to malformation; previous child with a malformation; } \\
\text { previous unexplained perinatal death }\end{array}$ \\
\hline BMI >35 at antenatal booking \\
\hline $\begin{array}{l}\text { BMI = body mass index; } G D M=\text { gestational diabetes mellitus; } L G A=\text { large for } \\
\text { gestational age; OGTT = oral glucose tolerance test; } R P G=\text { random plasma } \\
\text { glucose; } S D=\text { standard deviation }\end{array}$ \\
\hline $\begin{array}{l}\text { such as RPG, is also controversial. RPG is a quick, simple and inexpensive } \\
\text { test that measures plasma glucose at a random time, regardless of the } \\
\text { time of the last meal. There are few studies on RPG as a screening test } \\
\text { for GDM. Although the results are not conclusive they suggested that the } \\
\text { RPG test may result in high false positivity and false negativity. }{ }^{21,22} \text { The } \\
\text { latest NICE guideline did not recommend using RPG to assess the risk of } \\
\text { developing GDM. }{ }^{12} \text { A previous systematic review found limited evidence } \\
\text { to support the use of RPG in screening. }{ }^{23} \text { In contrast, a recent study } \\
\text { suggested that RPG predicts GDM better than maternal age or BMI. }{ }^{24}\end{array}$ \\
\hline
\end{tabular}

We hypothesised that women with GDM would have elevated blood glucose levels before its diagnosis. The aim of this study was to assess the performance of RPG in gestational weeks 23-28, alone and/or in combination with maternal $\mathrm{BMl}$ and age, in identifying women who will develop GDM.

\section{Material and methods}

In a retrospective cohort study, the data for all pregnant women who gave birth in Västernorrland County, Sweden, over a 2-year period (1 January 2015 to 31 December 2016) were obtained. This study was approved by the Regional Ethical Review Board in Umeå, Sweden.

The Swedish electronic medical record database for prenatal care and childbirth, Obstetrix (Siemens Corporation, Upplands Väsby, Sweden), was searched for women meeting the criteria defined below. In Obstetrix, each pregnancy is followed in a logical and structured manner, from enrolment in a prenatal healthcare centre to the arrival at the maternity unit and the time of delivery. Data for pregnancies fulfilling our criteria were compiled into an Excel file. For each pregnancy, the records were searched manually for the RPG value at gestational weeks 23-28, and whether or not each woman developed GDM was recorded. Women were excluded for the following reasons: incomplete data recorded, lack of an RPG test in gestational weeks 23-28, pre-existing diabetes mellitus and/or other metabolic disease, or a diagnosis of diabetes other than GDM during pregnancy. Maternal hypothyroidism was not considered an exclusion criterion.

The main screening strategy for GDM was based on repeated capillary RPG measurements made four to six times during pregnancy. The risk factors for GDM that indicated a 2-hour $75 \mathrm{~g}$ OGTT, according to regional screening practices, are presented in Table 1. The main diagnostic criterion for GDM was based on the one-step 2-hour $75 \mathrm{~g}$ OGTT. After 2 hours, a capillary RPG of $\geq 10.0 \mathrm{mmol} / \mathrm{l}$ (considered equivalent to venous blood glucose $\geq 9.0 \mathrm{mmol} / \mathrm{l}$ ) was considered pathological and defined as GDM. Fasting capillary glucose values were not considered as a diagnostic criterion for GDM.
IBM SPSS Statistics version 24.0 (IBM Corp., Armonk, New York, USA) was used for all statistical analyses. The ability of capillary RPG, maternal BMI, and age to predict GDM was tested with receiver-operating characteristic (ROC) curves. The variables presented in Table 2 were compared between the two groups of women: with and without GDM, using an independentsamples $t$ test and $\chi^{2} /$ Fischer's tests for continuous and categorical variables, respectively. In this study, the sample size calculations were based on the diagnostic test accuracy under different conditions and test results. The required sample size was calculated to be $n=4,800$ based on an estimated prevalence of GDM by the latest national statistics in southern Sweden ${ }^{25}(2.6 \%$ ), a margin error of 0.07 (confidence width $=0.14$ ) with $95 \%$ confidence, and an estimated sensitivity of $80 \%$.

\section{Results}

Data for 5,383 pregnancies were initially obtained. After the exclusion criteria were applied, a total of 4,698 pregnancies qualified for the final statistical analysis (see flow-chart, Figure 1).

Women without pre-existing diabetes who received a diagnosis of diabetes during pregnancy were considered to have GDM. ${ }^{11}$ However, the persistence of diabetes was not followed postpartum. The number of pregnancies associated with GDM was 59 (out of 943 OGTT), equivalent to a prevalence of $1.3 \%$ in the study population.

The baseline characteristics of all pregnancies and subgroups, according to the presence or absence of GDM, are shown in Table 2. Women with GDM were older $(p<0.01)$ and had a higher $\mathrm{BMI}(\mathrm{p}<0.001)$ than those without GDM. Parity $(p<0.001)$ and foetal birth weight $(p<0.01)$ were higher among the women with GDM. There was no statistically significant association between GDM and the number of births.

The abilities of RPG, maternal BMI, and age to predict GDM were tested with ROC curves (Figure 2). The thresholds that generated the best overall performance for each variable and different combinations of variables were assessed. The threshold/combined thresholds generating the maximum sum of sensitivity and specificity were considered to show the best overall performance.

RPG predicted GDM fairly well ( $n=59$ with RPG; area under the curve [AUC] 0.73; 95\% confidence interval [Cl] 0.66-0.80). The threshold value of RPG $\geq 9.0 \mathrm{mmol} / \mathrm{l}$ showed a sensitivity of $15.3 \%$ and a specificity of $99.7 \%$. A cut-off value of RPG $\geq 7.0 \mathrm{mmol} / \mathrm{l}$ showed greater sensitivity (37.3\%) and a specificity of $93.1 \%$. To achieve $100 \%$ sensitivity, the cut-off for RPG had to be set at RPG $\geq 4.3 \mathrm{mmol} / \mathrm{l}$, which would have identified all cases of GDM, but the specificity would have decreased to $14.6 \%$. The best overall performance of sensitivity and specificity was obtained with RPG $\geq 5.5 \mathrm{mmol} / \mathrm{l}$. Using this cut-off value, RPG predicted GDM with a sensitivity of $69.5 \%$ and a specificity of $60.9 \%$ (Table 3).

BMI predicted GDM with similar AUC values, as did RPG ( $n=57$ with BMl; AUC 0.75; 95\% Cl 0.68-0.82). The threshold value of $\mathrm{BMI}>35$ had a sensitivity of $36.8 \%$ and a specificity of $94.3 \%$. The overall best performance of sensitivity and specificity was achieved with a threshold of $\mathrm{BMI} \geq 27.9$, with $63.2 \%$ sensitivity and $74.8 \%$ specificity (Table 3 ).

Maternal age performed poorly as a screening factor for GDM ( $n=59$ with age; AUC 0.61; 95\% Cl 0.53-0.68) (Table 3). The performance of different combinations of RPG, maternal BMI, and age in predicting GDM was controlled. The combination of $\mathrm{RPG} \geq 7$ and $\mathrm{BMI} \geq 27.9$ showed the best performance, with a sensitivity of $75.4 \%$ and a specificity of $70.1 \%$ (ROC AUC 0.75). Generally, compared with the performance of 
Table 2: Baseline characteristics of all patients and patients with/without gestational diabetes mellitus

\begin{tabular}{|c|c|c|c|c|c|c|c|c|}
\hline & & \multicolumn{2}{|c|}{ All patients $(n=4,698)$} & \multicolumn{2}{|c|}{ Without GDM $(n=4,639)$} & \multicolumn{2}{|c|}{ With GDM $(n=59)$} & \multirow{2}{*}{$\begin{array}{l}\text { p-value } \\
\text { subgroups }\end{array}$} \\
\hline & & mean (SD) & $\mathrm{n}(\%)$ & mean (SD) & n $(\%)$ & mean (SD) & $\mathrm{n}(\%)$ & \\
\hline Age & & $29.4(5.2)$ & & $29.4(5.0)$ & & $31.4(5.5)$ & & $<0.01$ \\
\hline BMI & & $25.5(5.2)$ & & $25.4(5.1)$ & & $31.9(7.8)$ & & $<0.001$ \\
\hline \multirow[t]{3}{*}{ Parity } & 0 & & $1,970(41.9)$ & & $1,950(42.0)$ & & 20 (33.9) & $<0.001$ \\
\hline & 1 & & $1,623(34.5)$ & & $1,613(34.8)$ & & $10(16.9)$ & \\
\hline & $\geq 2$ & & $1,071(22.8)$ & & $1,051(22.7)$ & & $29(49.2)$ & \\
\hline \multirow[t]{3}{*}{ Number of births } & 1 & & $4,634(98.6)$ & & $4,576(98.6)$ & & 58 (98.3) & NS \\
\hline & 2 & & $63(1.3)$ & & $62(1.3)$ & & $1(1.7)$ & \\
\hline & 3 & & $1(0.0)$ & & $1(0.0)$ & & $0(0.0)$ & \\
\hline Birth weight (g) & & $3,557.3(551.7)$ & & $3,554.7(550.0)$ & & $3,761.2(645.3)$ & & $<0.01$ \\
\hline
\end{tabular}

p-values when comparing the two groups of women, with and without GDM, are presented.

$B M I=$ body mass index; $G D M=$ gestational diabetes mellitus; $N S=$ non-significant; $S D$ = standard deviation

\section{Figure 1: Study flow chart}

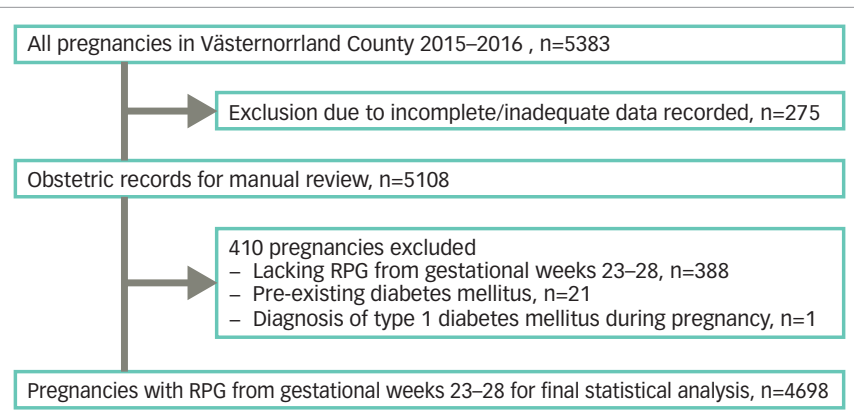

$R P G=$ random plasma glucose

individual factors, increased sensitivity was obtained by combining the factors, but at the cost of lower specificity and lower ROC AUC (Table 4).

\section{Discussion}

There is no consensus regarding optimal standard for screening and diagnosis of GDM. The results of this study show that a capillary RPG at gestational weeks 23-28 has only a fair performance in identifying women who develop GDM. Maternal BMI as a screening factor showed a slightly better performance, whereas the performance of maternal age was poor. On the other side, combining RPG and BMI increases the overall performance and the sensitivity, while the specificity of the test decreases.

RPG assessment is a convenient screening method that can be applied at a prenatal visit. Some studies suggested that the RPG measurement in early period of gestation may show negative results with a low positive predictive value (6.7\%). ${ }^{21}$ The changes in maternal carbohydrate metabolism and the increasing insulin resistance are well established by 24 weeks of gestation and GDM is most likely to develop after this time as the capacity of the pancreas to adapt to the increased need of insulin is impaired, especially in women with predisposing factors. ${ }^{3}$ It is thus reasonable to assume that elevated blood glucose levels can, at the earliest, be detected around and after gestational week 24 . The benefits of earlier screening are unclear and the US Preventive Services Task Force therefore recommends screening for GDM after gestational week $24 .{ }^{26}$ Screening of GDM in Sweden is based on repeated capillary RPG measurements during pregnancy, and an RPG should be measured around gestational week 24-25. ${ }^{14}$ However, the recommendation is not definite and slight variation in sampling time may occur. As a
Figure 2: Receiver-operating characteristic curves show the performance of random plasma glucose, maternal body mass index and maternal age in predicting gestational diabetes mellitus

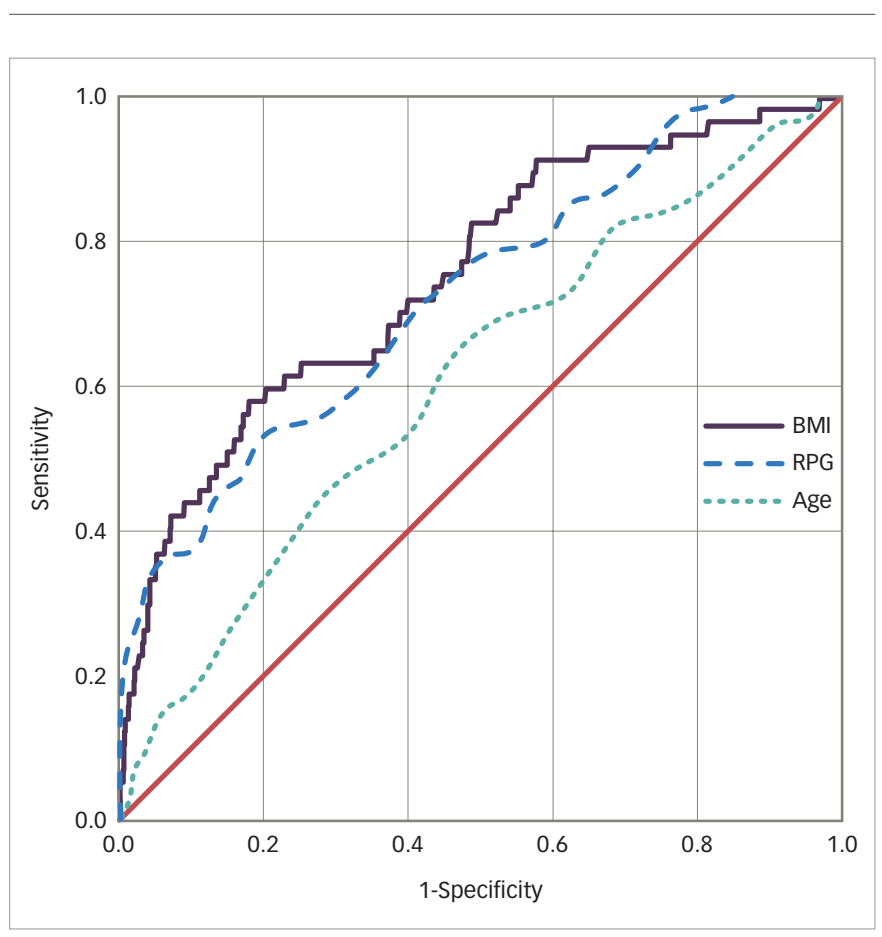

$B M I=$ body mass index $; R P G=$ random plasma glucose

consequence, some women might have an RPG value at gestational week 23. We thus included women with RPG values registered at gestational weeks 23-28.

Previous studies on the performance of random glucose measurement in screening for GDM show considerable heterogeneity in study design, diagnostic criteria, definitions and methods. In a systematic review, van Leeuwen et al. attempted to calculate a summary estimate of the performance of a random blood glucose test in screening for GDM. However, the author declared that the available evidence on the accuracy of a random glucose test in screening for GDM is limited, a single random glucose measurement was concluded to be inadequate to screen for GDM. ${ }^{23}$ Jowett et al. compared the performance of repeated measures of random venous blood glucose at gestational weeks 27-31 with a 2-hour $75 \mathrm{~g}$ OGTT. In the same line as in our study, they showed a low sensitivity and a high specificity for random blood 
Table 3: Performance of variables with different threshold values

\begin{tabular}{|c|c|c|}
\hline & Sensitivity (\%) & Specificity (\%) \\
\hline \multicolumn{3}{|c|}{ ROC: RPG (mmol/l) $(n=59)$ AUC $0.73 ; 95 \% \mathrm{Cl} \mathrm{0.66-0.80}$} \\
\hline$\geq 9.0$ & 15.3 & 99.7 \\
\hline$\geq 5.5$ & 69.5 & 60.9 \\
\hline$\geq 7.0$ & 37.3 & 93.1 \\
\hline$\geq 4.3$ & 100 & 14.6 \\
\hline \multicolumn{3}{|c|}{ ROC: BMI $(n=57)$ AUC $0.75 ; 95 \%$ Cl 0.68-0.82 } \\
\hline$>35$ & 36.8 & 94.4 \\
\hline$\geq 27.9$ & 63.2 & 74.8 \\
\hline$\geq 27$ & 63.2 & 69.8 \\
\hline$\geq 28$ & 61.4 & 75.2 \\
\hline$\geq 30$ & 52.6 & 83.1 \\
\hline$\geq 18.7$ & 100 & 3.1 \\
\hline \multicolumn{3}{|c|}{ ROC: Age $(n=59)$ AUC $0.61 ; 95 \%$ Cl 0.53-0.68 } \\
\hline$\geq 30$ & 64.4 & 53.2 \\
\hline$\geq 35$ & 30.5 & 82.6 \\
\hline$\geq 25$ & 88.1 & 11.8 \\
\hline$\geq 19$ & 100 & 0.8 \\
\hline
\end{tabular}

$A \cup C=$ area under curve; $B M I=$ body mass index $\mathrm{Cl}=$ confidence interval; $R O C=$ receiver-operating characteristic; $R P G=$ random plasma g/ucose.

glucose test; however, the performance of the test varied depending on the timing of the sample collection. On the other hand, the majority of women with impaired glucose tolerance would be missed, therefore the author concluded that random blood glucose measurement is not a sufficiently sensitive method for detecting GDM..$^{27}$ In another study, the performance of random blood glucose test in screening for GDM was compared with a $50 \mathrm{~g}$ OGTT at 24-28 weeks of gestation. The $50 \mathrm{~g}$ OGTT is the most widely accepted method to screen GDM in north America. ${ }^{26}$ Their results showed better performance of the $50 \mathrm{~g}$ OGTT, while a study by Mathai et al. ${ }^{22}$ suggested that neither RPG nor the glucose challenge test is a useful screening method for GDM..$^{28}$ In all the abovementioned studies, a venous blood glucose test was used instead of a capillary RPG and tests performed during different gestational weeks, which makes the comparison between studies difficult.

In our study, RPG measured via capillary blood sampling, and it can be accounted as a limitation of this study. According to international consensus, the diagnosis of diabetes should be based on venous sampling. ${ }^{29}$ Venous and capillary values are considered to reflect different phases in the body's glucose metabolism, which may vary from one individual to another, which means they are not directly interchangeable. Capillary values are believed to reflect glucose absorbed from the intestine and venous host elimination and the body's need and ability to metabolise glucose. ${ }^{30}$ Venous sampling is complicated and time consuming, as well as being more uncomfortable for the patient. Capillary analysis has the advantage of giving an immediate response and simplifies handling compared with the samples being sent to the laboratory for analysis; however, measurement safety is usually worse in capillary test apparatus compared with the central laboratory instruments. ${ }^{31}$

Another limitation of this study is that we have not taken into account the ethnicity factor. Ethnicity has long been described as a major risk factor for the development of GDM.
Table 4: Performance of variables by combinations

\begin{tabular}{|c|c|c|c|c|}
\hline & & $\begin{array}{l}\text { Sensitivity } \\
(\%)\end{array}$ & $\begin{array}{l}\text { Specificity } \\
(\%)\end{array}$ & ROC AUC \\
\hline $\mathrm{RPG}(\mathrm{mmol} / \mathrm{l})$ & \multicolumn{4}{|l|}{$\mathrm{BMI}$} \\
\hline 7.0 & 27.9 & 75.4 & 70.1 & $0.75 ; 95 \% \mathrm{Cl} 0.68-0.82$ \\
\hline 7.0 & 30 & 66.7 & 77.8 & \\
\hline 7.0 & 28 & 73.7 & 70.5 & \\
\hline BMI & \multicolumn{4}{|l|}{ Age } \\
\hline 28 & 35 & 73.7 & 63.4 & $0.69 ; 95 \% \mathrm{Cl} 0.62-0.76$ \\
\hline 27.9 & 35 & 73.7 & 63.0 & \\
\hline 30 & 35 & 66.7 & 69.5 & \\
\hline $\mathrm{RPG}(\mathrm{mmol} / \mathrm{l})$ & \multicolumn{4}{|l|}{ Age } \\
\hline 7.0 & 35 & 57.6 & 77.1 & $0.68 ; 95 \%$ Cl 0.61-0.76 \\
\hline 5.5 & 35 & 79.7 & 51.2 & \\
\hline 9.0 & 35 & 40.7 & 82.4 & \\
\hline
\end{tabular}

The three best results are presented in descending order of performance. $A U C=$ area under curve; $B M I=$ body mass index; $C l=$ confidence interval; $R O C=$ receiver-operating characteristic; $R P G=$ random plasma g/ucose.

In contrast to our results, a recent study by Meek et al. showed that RPG have a good performance in screening for GDM (AUC 0.81; $95 \%$ $\mathrm{Cl} 0.80-0.83$ ), and RPG even performed better than predisposing factors for GDM (maternal age and BMI) when used as a screening test for $\mathrm{GDM}^{24}$ however, similar to our results, they also found that combining RPG and BMI, or BMl and age improved the sensitivity. The difference between studies can be explained by the fact that in the study by Meek et al., the study group consisted of pregnant women at early gestational age (12-16 weeks) while, in our study, data collected were from among pregnant women at later gestational ages (23-28 weeks).

The threshold value of RPG $\geq 9.0 \mathrm{mmol} / \mathrm{l}$ that has been used in this study to determine if a further OGTT is needed, was able to identify $15.3 \%(n=9)$ of women with GDM. On the other hand, the number of healthy women with an RPG value above this cut-off value was very low $(0.3 \%, n=12)$, therefore, this threshold value $(\geq 9.0 \mathrm{mmol} / \mathrm{l})$ may fit better in women with no additional predisposing factors for GDM. On the other hand, lower threshold (<9.0 mmol/l) would identify more cases of GDM, but the number of false positive samples would be increased and more healthy women would need to undergo an OGTT.

In Sweden, the main screening strategy for GDM is based on repeated capillary random blood glucose and assessment of risk factors for developing $\mathrm{GDM}^{-14,15}$ however, this selective screening strategy is suggested to be insufficient when compared to an OGTT.20,13 Our results also confirm that selective screening is insufficient because neither of the variables we controlled (commonly used in selective screening) could show compelling performance alone or combined. In countries with growing epidemics of obesity and diabetes, many women in most populations will have some risk factors for GDM depending on the criteria used. Thus, the implementation of riskfactor-based screening will require most women to be tested. On the other hand, OGTT screening misses some patients with increasing carbohydrate intolerance that do not meet the current criteria for the diagnosis of GDM because of the rate of unavoidable no-shows. ${ }^{32,33}$ The Hyperglycemia and Adverse Pregnancy Outcomes study demonstrates that maternal hyperglycaemia, even at a level below that diagnostic of GDM, leads to increased morbidity during pregnancy and is associated with adverse pregnancy outcomes. ${ }^{5}$ It is open to speculation how the 
screening by a combination of risk factors and an OGTT may change the number of missed diagnoses.

Based on national statistics in Sweden, the prevalence of GDM is highest in Southern Sweden, where universal screening with an OGTT has been practiced since $1995 .{ }^{25}$ The difference in prevalence numbers for GDM in this study (1.3\% versus $2.6 \%$ in southern Sweden) is presumably due to the screening practice and indicates that there could be a substantial underdiagnoses of GDM in the remaining parts of Sweden. It appears that the diagnostic accuracy for GDM is higher for an OGT than a capillary RPG and, therefore, offering an OGT with venous sampling to all pregnant women should be the most reliable screening strategy. Although the recommendation to undertake OGTT in every woman to screen for GDM would have a defined cost, there might be a long-term economic advantage in the early diagnosis and management of GDM, as women at risk of developing diabetes in the future could be detected early on, with the possibility for primary preventive actions to be taken.

In conclusion, it is known that untreated GDM leads to increased maternal and perinatal complications, but the screening methods for diagnosis remain controversial. Capillary RPG is a convenient and inexpensive test for screening for GDM, but our results suggest that sensitivity is poor. Future research on screening methods for GDM should be conducted in a prospective design.
1. National Diabetes Data Group. Classification and diagnosis of diabetes mellitus and other categories of glucose intolerance. Diabetes. 1979;28:1039-57.

2. Metzger BE, Coustan DR. Summary and recommendations of the Fourth International Workshop-Conference on Gestationa Diabetes Mellitus. The Organizing Committee. Diabetes Care. 1998;21(Suppl 2):B161-7.

3. Hod M, Kapur A, Sacks DA, et al. The International Federation of Gynecology and Obstetrics (FIGO) Initiative on gestational diabetes mellitus: A pragmatic guide for diagnosis, management, and care. Int J Gynaecol obstet. 2015;131(Suppl 3):S173-211.

4. World Health Organization. Diagnostic Criteria and Classification of Hyperglycaemia First Detected in Pregnancy. 2013. Available at: https://apps.who.int/iris/ bitstream/handle/10665/85975/WHO_NMH_MND_13.2_eng. pdf? sequence $=1$ (accessed 11 June 2019)

5. Group HSCR, Metzger BE, Lowe LP, et al. Hyperglycemia and adverse pregnancy outcomes. N Eng/ J Med. 2008;358:1991-2002

6. Jensen DM, Korsholm L, Ovesen P, et al. Adverse pregnancy outcome in women with mild glucose intolerance: is there a clinically meaningful threshold value for glucose? Acta Obstet Gynecol Scand. 2008;87:59-62.

7. McIntyre HD, Metzger BE, Coustan DR, et al. Counterpoint: Establishing consensus in the diagnosis of GDM following the HAPO study. Curr Diab Rep. 2014;14:497.

8. International Association of Diabetes and Pregnancy Study Groups Consensus Panel. International association of diabetes and pregnancy study groups recommendations on the diagnosis and classification of hyperglycemia in pregnancy. Diabetes Care. 2010;33:676-82.

9. Caughey AB, Turrentine M. ACOG Practice Bulletin No. 190 Gestational Diabetes Mellitus. Obstet Gynecol. 2018;131:e49-e64.

10. Agarwal MM. Gestational diabetes mellitus: An update on the current international diagnostic criteria. World I Diabetes. 2015;6:782-791.

11. Gränsvärden för graviditetsdiabetes. Stöd för beslut om behandling. Stockholm: Socialstyrelsen; 2015. Available at: www.socialstyrelsen.se/globalassets/sharepoint-dokument/ artikelkatalog/ovrigt/2015-6-52.pdf. Accessed 5 July 2019
12. National Institute of Health and Care Excellent. Diabetes in pregnancy: management from preconception to the postnatal period. 2015. Available at: www.nice.org.uk/guidance/ng3 (accessed 11 June 2019).

13. Ostlund I, Hanson U. Repeated random blood glucose measurements as universal screening test for gestational diabetes mellitus. Acta Obstet Gynecol Scand. 2004;83:46-51.

14. Lindqvist $M$, Persson $M$, et al. No consensus on gestational diabetes mellitus screening regimes in Sweden: pregnancy diabetes mellus screen ing regimes in Sweden: pregnancy . Pregnancy Childbirth. 2014;14:185.

15. Fadl HE, Simmons D. Trends in diabetes in pregnancy in Sweden 1998-2012. BMJ Open Diabetes Res Care. 2016;4:e000221.

16. Lind T, Phillips PR. Influence of pregnancy on the 75-g OGTT. A prospective multicenter study. The Diabetic Pregnancy Study Group of the European Association for the Study of Diabetes. Diabetes. 1991;40:(Suppl 2):8-13.

17. Xiong X, Saunders LD, Wang FL, Demianczuk NN. Gestational diabetes mellitus: prevalence, risk factors, maternal and infant outcomes. Int J Gynaecol Obstet. 2001;75:221-8.

18. Ben-Haroush A, Yogev Y, Hod M. Epidemiology of gestational. diabetes mellitus and its association with Type 2 diabetes. Diabet Med. 2004;21:103-13.

19. Simmons $D$, Devers $M C$, Wolmarans $L$ \& Johnson E Difficulties in the use of risk factors to screen for gestational diabetes mellitus. Diabetes Care. 2009:32:e8.

20. Dahanayaka NJ, Agampodi SB, Ranasinghe OR, et al. Inadequacy of the risk factor based approach to detect gestational diabetes mellitus. Ceylon Med J. 2012;57:5-9.

21. Maegawa Y, Sugiyama T, Kusaka $\mathrm{H}$, et al. Screening tests for gestational diabetes in Japan in the 1 st and 2nd trimester of pregnancy. Diabetes Res Clin Pract. 2003;62:47-53.

22. van Leeuwen $\mathrm{M}$, Zweers EJ, Opmeer BC, et al. Comparison of accuracy measures of two screening tests for gestationa diabetes mellitus. Diabetes Care. 2007;30:2779-84.

23. van Leeuwen M, Opmeer BC, Yilmaz Y, et al. Accuracy of the random glucose test as screening test for gestational diabetes mellitus: a systematic review. Eur I Obstet Gynecol Reprod Biol. 2011;154:130-5
24. Meek CL, Murphy HR, Simmons D. Random plasma glucose in early pregnancy is a better predictor of gestational diabetes diagnosis than maternal obesity. Diabetologia. 2016;59: $445-52$

25. Ignell C, Claesson R, Anderberg E, Berntorp K. Trends in the prevalence of gestational diabetes mellitus in southern Sweden, 2003-2012. Acta Obstet Gynecol Scand. 2014;93:420-4.

26. Moyer VA. Screening for gestational diabetes mellitus: U.S. Preventive Services Task Force recommendation statement. Ann Intern Med. 2014:160:414-20.

27. Jowett NI, Samanta AK, Burden AC. Screening for diabetes in pregnancy: is a random blood glucose enough? Diabet Med. 1987:4:160-3.

28. Mathai M, Thomas TJ, Kuruvila S, Jairaj P. Random plasma glucose and the glucose challenge test in pregnancy. Natl Med J India. 1994;7:160-2.

29. World Health Organization. Definition and diagnosis of diabetes mellitus and intermediate hyperglycaemia. Report of a WHO/IDF consultation. 2006. Available at: https://apps.who int/iris/bitstream/handle/10665/43588/9241594934_eng.pdf; jsessionid=22A41627129788A43C1COF9FE38B7C89? sequence $=1$

30. Stahl M, Brandslund I, Jorgensen LG, et al. Can capillary whole blood glucose and venous plasma glucose measurements be used interchangeably in diagnosis of diabetes mellitus? Scand J Clin 120 lnvest 2002:62:159-66.

31. Carstensen B, Lindstrom J, Sundvall J, et al. Measurement of blood glucose: comparison between different types of specimens. Ann Clin Biochem. 2008:45:140-8.

32. Sermer $\mathrm{M}$, Naylor $\mathrm{CD}$, Gare $\mathrm{DJ}$, et al. Impact of increasing carbohydrate intolerance on maternal-fetal outcomes in 3637 women without gestational diabetes. The Toronto TriHospital Gestational Diabetes Project. Am I Obstet Gynecol. 1995; 173:146-56

33. Gupta Y, Kalra B, Baruah MP, et al. Updated guidelines on screening for gestational diabetes. Int I Womens Health 2015;7:539-50.

34. Marsal K, Persson PH, Larsen T, et al. Intrauterine growth curves based on ultrasonically estimated foetal weights. Acta Paediatr. 1996;85:843-8. 